\title{
Metallorganic Chemical Vapor Deposition and Characterization of $\mathrm{TiO}_{2}$ Nanoparticles
}

\author{
Oh-Jin Jung, ${ }^{\circ}$ Sam-Hyeok Kim, Kyung-Hoon Cheong, W. Li, ${ }^{,}$and S. Ismat Saha ${ }^{\dagger}$ \\ School of Enwironmental Engineering. Chosth Lniversity, Gu'ang-ju 501-759, Korea \\ Department of Aaterials Science and Engineering, and Phvsical and Astronomv: \\ Unversity of Delan are, Newark, DE 19716, LSA \\ Received September 7, 2002
}

\begin{abstract}
$\mathrm{TiO}_{2}$ nanoparticles were synthesized using the metallorganic chenucal vapor deposition process. Particles with and without metal ion dopants were obtained. X-ray photoelectron and energy dispersive X-ray spectroscopic measurements confirmed the stoichiometry of the $\mathrm{TiO}_{2}$ nanoparticles. X-ray diffraction patterns showed a polycrystalline anatase structure of $\mathrm{TiO}_{2}$. Transmission electron microscopy revealed that these particles are of nanoscale dimensions. Exact particle size and size distribution analy ses were carried out by dynamic light scattering. The average particle size was determined to be $22 \mathrm{~nm}$. The nanosize particles provided large surface area for photocatalysis and a large number of free surface-charge carriers. which are crucial for the enhancement of photocataly tic activity. To improve the photocatalytic activity, metal ions, including transition metal ions $\left(\mathrm{Pd}^{2-} . \mathrm{Pt}^{4+} . \mathrm{Fe}^{3-}\right)$ and lanthanide ion $\left(\mathrm{Nd}^{3-}\right)$ were added to pure $\mathrm{TiO}$. nanoparticles. The effects of dopants on photocatalytic kinetics were investigated by the degadation of 2-chlorophenol under an ultraviolet light source. The results showed that the $\mathrm{TiO}_{2}$ nanoparticles with the metal ion dopants have higher photocatalytic activity than undoped $\mathrm{TiO}_{2}$. The $\mathrm{Nd}^{3-}$ ion of these dopant metal ions showed the highest catalytic activity. The difference in the photocatalytic activity with different dopants is related to the different ionic radii of the dopants
\end{abstract}

Key Words : $\mathrm{TiO}_{2}$ nanoparticles. Metal ion dopants. MOCVD. Photocataly sis

\section{Introduction}

With the increase in the public awareness and concern about environmental pollutants. novel. stable cheap. nontoxic and high catalytic activity treatment methods are in demand for the detoxification and degradation of harmful organic compounds in both aqueous and gaseous media. Besides the commonly used semiconductor oxides such as $\mathrm{ZnO}^{1.2} \mathrm{SnO}_{2}{ }^{3}$ and $\mathrm{Fe}_{2} \mathrm{O}_{3}{ }^{+} \mathrm{TiO}_{2}$ nanoparticles offer additional advantages in that $\mathrm{TiO}_{2}$ is low cost chemically inert. highly photoactive and has suitable band gap $\left(\mathrm{E}_{\mathrm{g}}=3.2 \mathrm{eV}\right)$ in which its redox potential of the $\mathrm{H}_{2} \mathrm{O} / \mathrm{OH}$ couple $(-2.8 \mathrm{eV})$ lies. It is also self regenerating and recyclable. These properties make $\mathrm{TiO}_{2}$ a prime candidate for broad applications. including gas sensors and photocatalysts. However. the major impediment to its widespread application. particularly' indoors. resides in the fact that $\mathrm{TiO}_{2}$ absorbs near-ultraviolet (UV) light ( $E_{\mathrm{g}}=3.2 \mathrm{eV}$ for anatase). This band gap does not match very well with solar light. Several solutions have been proposed to increase visible light absorption in $\mathrm{TiO}_{\text {. }}$. including doping with transition metals ${ }^{5-8}$ and dye sensitization. ${ }^{9}$

In addition to the chemical modification of $\mathrm{TiO}_{2}$ to induce visible light absorption. considerable enhancement of the absorption can also be achieved in small nanocrystals where the surface to volume ratio is large and the fraction of the surface atoms is sufficiently large. The main mechanism of

\footnotetext{
*Corresponding Author: Phone: +82-62-230-6644, e-mail: oijung âchosunac.lr
}

light absorption in pure semiconductors is the interband electron transition. These transitions are direct because the momentum that the electron obtains from light waves is small in comparison with $\mathrm{l} / \mathrm{a}$. where " $\mathrm{a}$ " is the lattice constant. This absorption is especially small in direct-forbidden gap semiconductors. for which the direct electron transitions between the band centers are prolibited by the crystal symmetry. This is the case for $\mathrm{TiO}_{2}$. However. momentum is not conserved if the absorption takes place at the boundary of the crystal. e.g. at the surface or at the interface between two crystals. The possibility of indirect electron transitions there can result in the essential enhancement of light absorption. This means that considerable enhancement of the absorption can be observed in small nanocrystals. where the surface to volume ratio is very high and the share of the surface atoms is sufficiently large. The particle size at which the interface enhancement of the absorption becomes significant is around $20 \mathrm{~nm}$. An additional advantage obtained in nanoparticles in the few nm size regimes is that the large surface/volume ratio makes possible the timely utilization of photogenerated carriers in interfacial processes..$^{[0.1]}$ The challenge is to develop a process that can produce nanoparticles of the desired size with a relatively narrow size distribution

$\mathrm{TiO}_{2}$ can be synthesized by several processes. including sulfate process. ${ }^{12}$ chloride process. ${ }^{12}$ impregnation. ${ }^{5}$ coprecipitation..$^{13}$ sol-gel. ${ }^{1+163}$ hydrothermal method. ${ }^{8.17 .18}$ direct oxidation of $\mathrm{TiCl}_{4}{ }^{1 .}$ and metallorganic chemical vapor deposition (MOCVD) method. ${ }^{30-23}$ Most non-CVD processes require 
multiple steps to obtain monodispersed particles. In this study $\mathrm{MOCVD}$ was used to prepare $\mathrm{TiO}_{2}$ nanoparticles due to the ease and simplicity of this process. No further calcination. centrifuge or hydrothermal processing is required for crystallization or particle refinement. The control of size distribution is easily accomplished by simply controlling the temperature of the substrates and the flow rate of the precursors. Dopants can also be easily introduced into the reactor either through a solid source. separated from the Tiprecursor or mixed in with the precursor. In the present study: the effects of transition metal and lanthanide ion doping on the photocatalytic activity of $\mathrm{TiO}_{2}$ nanoparticles are discussed. Results of the degradation of 2-chlorophenol (2-CP) are presented. Low-level doping. particularly of $\mathrm{Nd}$. resulted in a large enhancement in the photoactivity of $\mathrm{TiO}_{2}$ nanoparticles for the photodegradation of $2-\mathrm{CP}$ and pentachlorophenol

\section{Experimental Section}

The $\mathrm{TiO}_{2}$ nanoparticles were prepared in the metallorganic chemical vapor deposition (MOCVD) system shown in Figure 1. A horizontal stainless steel tube reactor $5 \mathrm{~cm}$ in diameter and $75 \mathrm{~cm}$ in length was used. The central part of the reactor was extemally heated by a resistive heater. and a uniform temperature of up to $1000^{\circ} \mathrm{C}$ could be obtained in the $20 \mathrm{~cm}$ long central region. This was the region where all the sample collection was carried out. A mechanical pump was used to pump the reaction chamber down to a few mTorr base pressure. Quartz tubes. $3 \mathrm{~cm}$ in diameter and $12.5 \mathrm{~cm}$ long. and $5 \mathrm{~cm}$ diameter discs made of several layers of 475 mesh stainless steel screens were used in this experiment to collect the samples. Multiple layering was necessary to collect the particles efficiently: Above a critical temperature and precursor flow rate. nanocrystalline $\mathrm{TiO}_{2}$ films were obtained on quartz tubes. which were characterized separately: ${ }^{2+}$ Before the deposition. the surfaces of the substrates were cleaned by acetone methanol and de-ionized water. $\mathrm{Ti}\left[\mathrm{OCH}\left(\mathrm{CH}_{3}\right)_{2}\right]_{4}$ (titanium tetraisopropoxide. TTIP. 97\%) was used as the precursor for Ti. The liquid TTIF was placed in a bubbling chamber and $99.999 \%$ pure Ar was used as a

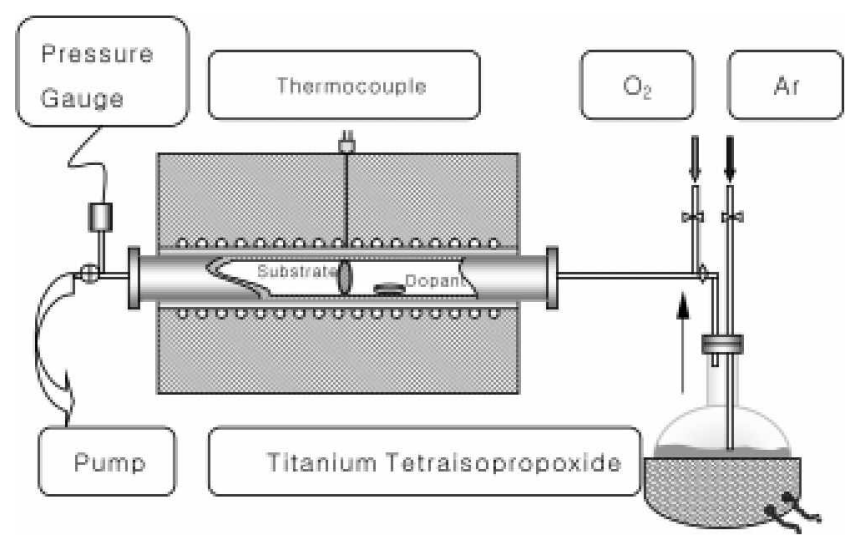

Figure 1. Schematic diagram of metallorganic chemical vapor deposition system. carrier gas. The precursor flow rate was controlled by adjusting the temperature of the bubbling chamber and/or the flow rate of the Ar flowing through it. $\mathrm{O}_{2}$ was added to the $\mathrm{Ar}$ and TTIP mixture in a baffle and the mixture was introduced into the reactor chamber for $\mathrm{TiO}_{2}$ formation. The flow rates for $\mathrm{O}_{2}$ and $\mathrm{Ar}$ were 20 and $2 \mathrm{sccm}$. respectively. $\mathrm{Nd}^{3-}, \mathrm{Fd}^{2-} . \mathrm{Pt}^{4-}$. $\mathrm{Fe}^{3-}$ ion dopants were studied and the precursors used for them were neodymium (III) acetylacetonate. palladium (II) acetylacetonate platinum (IV) acetylacetonate. and iron (III) acetylacetonate respectively. Dopant precursors. ty pically in the powder form. were placed in a $\mathrm{Cu}$ container. The container was placed directly at a pre-detennined position in the chamber. The position was determined by the temperature of the dopant. which. in turn. determined the vapor pressure of the dopant and thus the incorporation rate of the dopant in $\mathrm{TiO}_{2}$. In this experiment the deposition temperature was 600 ${ }^{\circ} \mathrm{C}$ for which the positions of the dopant precursors container for $\mathrm{Nd}^{3+}, \mathrm{Pd}^{2+}, \mathrm{Pt}^{4-}$, and $\mathrm{Fe}^{3+}$ were $21.5,19.18$, and $20 \mathrm{~cm}$ from the center of the chamber. respectively. The doping concentration as a function of the dopant temperature was measured.

Structural characterization of the doped and undoped $\mathrm{TiO}_{2}$ samples was carried out by X-ray diffraction (XRD). $\theta-2 \theta$ scans were recorded using $\mathrm{Cu} \mathrm{K}_{t z}$ radiation in a Rigaku DMax B diffractometer equipped with a graphite crystal monochromator. Precise $2 \theta$ positions and the full width at half maxima of the diffraction peaks were obtained using XFIT software 35 Compositions of the samples were determined by X-ray photoelectron spectroscopy (XPS) and energy dispersive X-ray spectroscopy (EDS). A SSI-M Probe XPS was used employing $\mathrm{Al} \mathrm{K}_{x z}$ exciting radiation. In addition to the survey scans. high resolution scans in the Ti $2 p$, dopant $4 d, O$ ls. and $\mathrm{C}$ ls regions were recorded. The Ti $2 \mathrm{p}$ and dopant $3 \mathrm{~d}$ or $4 \mathrm{~d}$ regions were used to measure the composition of the nanoparticles and to ascertain the valance states of $\mathrm{Ti}$ and the dopant. The measurement of average particle size and surface morphology were performed with Amray 1810T scauming electron microscopy (SEM). Transmission electron microscopy (TEM) was done in a JEOL 2000 FX TEM in order to verify the nanosize and polycrystalline structures of the particles. The size distribution of particles was investigated by Lexel 95 dy'namic light scattering (DLS) apparatus. using a 488-nm laser source. To reduce the agglomeration of particles that were dispersed in methanol solvent. a 125 -Watts and $50 / 60-\mathrm{Hz}$ ultrasonic cleaner was utilized to sonicate the particle solution for about 3 minutes and a $0.45-\mu \mathrm{m}$ filter was used to remove large agglomerations before the light scattering experiment.

Photodegradation experiments were performed in the photocataly'tic reactor system. This bench-scale system consisted of a cy lindrical pyrex-glass cell. $12 \mathrm{~cm}$ inside diameter and $30 \mathrm{~cm}$ length, with an inside reflective surface. A 100 watt $\mathrm{Hg}$ lamp was used. which was immersed in the solution with an air-cooled jacket. The maximum energy emission of $\mathrm{UV}$ at the wavelength of $365 \mathrm{~nm}$ was achieved 4 minutes after the lamp was tumed on. At the cooling jacket. an energy density of $5.3 \mathrm{~mW} / \mathrm{cm}^{2}$ was measured and the photon 


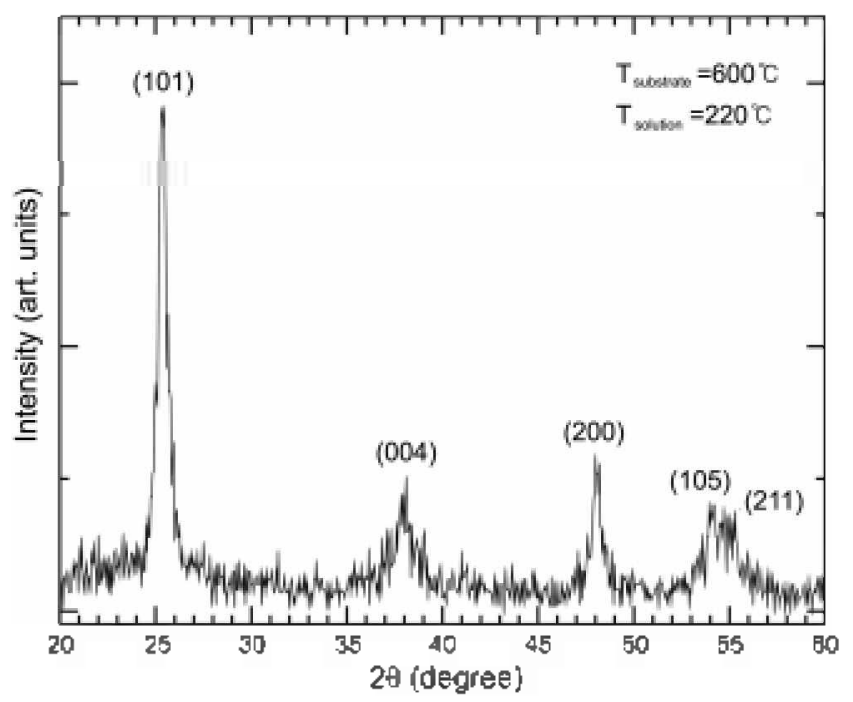

Figure 2. XRD pattem of $\mathrm{Nd}$ doped $\mathrm{TiO}_{2}$ nanoparticles. All diffraction peaks belong to the anatase phase.

flux was calculated to be $4.42 \times 10^{-4}$ Einstein/min. An aqueous solution ( $1000 \mathrm{~mL}$ ) of 2-CP and the stainless steel mesh with $10 \mathrm{mg} \mathrm{TiO}_{2}$ nanoparticles were placed in the photoreactor cell. A magnetic stirrer was used in the suspension and $\mathrm{O}_{2}$ was supplied through compressed air for the oxidation reaction. During illumination. the $\mathrm{pH}$ value of the suspension was controlled at 9.5. After illumination. samples were collected at regular intervals in a test-tube and each sample suspension was filtered by $0.2-\mu \mathrm{m}$ filter and then analyzed by a high performance liquid chromatograph (HPLC: Hewlett Packard series 1100 system) equipped with an UV detector $\left(\lambda_{\text {max }}=210 \mathrm{~mm}\right)$ and column [Eclipse XDB$\left.\mathrm{C}_{1 \mathrm{~s}}(50 \mathrm{~nm} \times 0.5 \mathrm{~nm})\right]$. The eluent solvent was acetonitrile: the buffer solution was $\mathrm{H}_{3} \mathrm{PO}_{4} / \mathrm{NaH}_{2} \mathrm{PO}_{4}$ and $\mathrm{pH}=3.0$.

\section{Results and Discussion}

Figure 2 is a XRD pattern for $\mathrm{TiO}_{2}$ nanoparticles doped with $\mathrm{Nd}$ collected on a stainless steel mesh substrate. The particles were collected at $600^{\circ} \mathrm{C}$ substrate temperature and $220^{\circ} \mathrm{C}$ TTIP precursor temperature. The positions of (101). (004). (200). (105) and (211) diffraction peaks confirms that the particles are polycrystalline with an anatase structure that has a tetragonal Bravais lattice. The full width at half maxima (FWHM) of the XRD peaks were measured to calculate the average particle size. using Scherrer's fomula. ${ }^{26}$ The average particle size was calculated to be approximately $27 \mathrm{~nm}$. $\mathrm{TiO}_{2}$ in anatase form is believed to be the most efficient photocataly'st during chemical reactions ${ }^{27.2 x}$. There were no other detectable peaks in the XRD patten to suggest the presence of $\mathrm{TiO}_{2}$ in the rutile structure. In addition. no dopant related diffraction peaks were observed. The detection limit for XRD was about 1 at.\%. If the dopant forms a separate phase below this detection limit. XRD would not be able to measure it. However. TEM results also did not show any separate dopant phase. The dopants went either into the interstitial positions or substitutional sites of $\mathrm{TiO}_{2}$ crystal

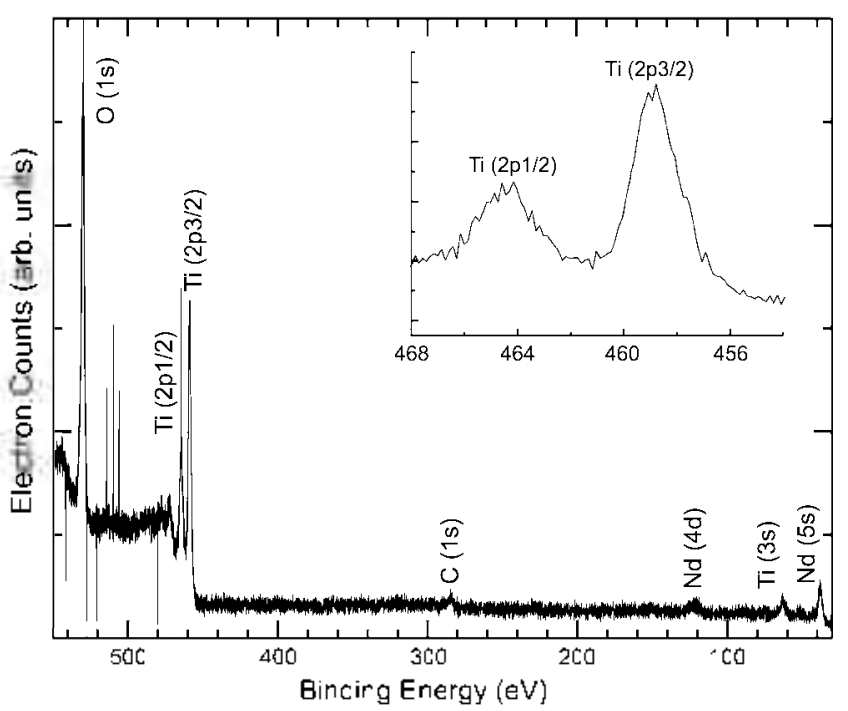

Figure 3. XPS survey and the high resolution Ti $2 p$ region of $\mathrm{Nd}$ doped $\mathrm{TiO}_{2}$ nanoparticles.

structure

The relative cation composition in the particles was determined by XPS and EDS. Figure 3 shows the XPS survey for a Nd doped sample. Only peaks associated with Ti. O. Nd and C were observed. The existence of a very small $\mathrm{C}$ peak is possibly due to surface contamination. $\mathrm{Nd}$ concentration was measured to be about 1 at. \%. This concentration was also confirmed by EDS (data not shown). which suggest a uniform distribution of $\mathrm{Nd}$ in the nanoparticles. The insert in Figure 3 is the magnified Ti $2 p$ region showing two peaks located at $458.4 \mathrm{eV}$ and $464.1 \mathrm{eV}$. respectively: The peaks for metallic $\mathrm{Ti}^{\circ}$ were expected at $453.8\left(2 \mathrm{p}_{30}\right)$ and $459\left(2 \mathrm{p}_{12}\right) \mathrm{eV}^{29}$ The shifts in Ti (2p $\left.\mathrm{p}_{32}\right)$ and $\mathrm{Ti}\left(2 \mathrm{p}_{1: 2}\right)$ peak positions are due to the presence of tetravalent $\mathrm{Ti}^{+-}$, as expected in $\mathrm{TiO}_{2}$. The change in the separation between the $\mathrm{Ti}\left(2 \mathrm{p}_{2: 2}\right)$ and $\mathrm{Ti}\left(2 \mathrm{p}_{1: 2}\right)$ peaks is also consistent with the formation of $\mathrm{TiO}_{2}{ }^{2.30} \mathrm{Nd}+\mathrm{d}$ peak occurs

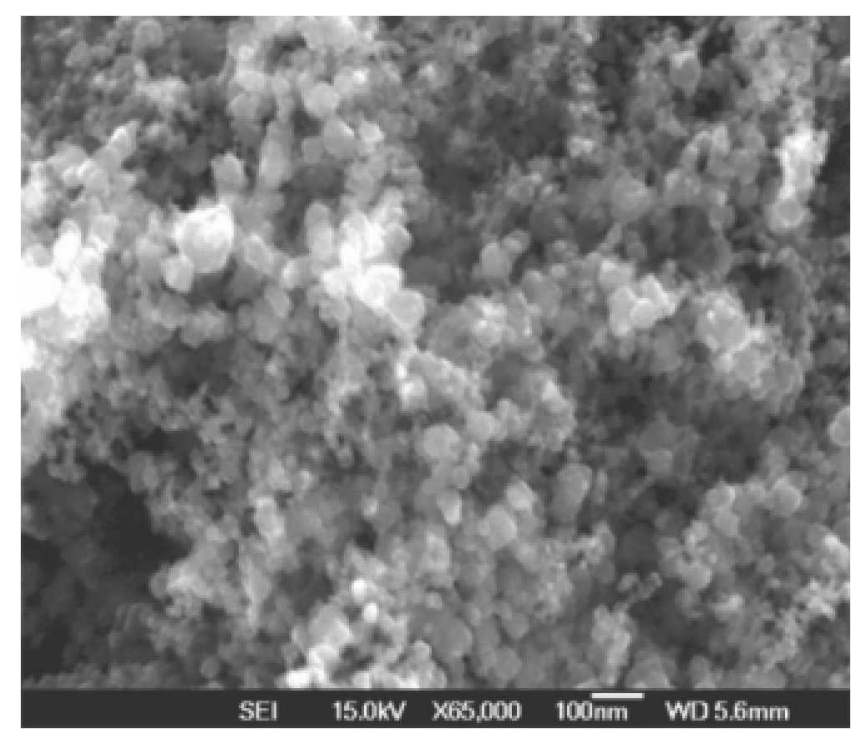

Figure 4 . SEM image of TiO? nanoparticles grown at $600^{\circ} \mathrm{C}$. 


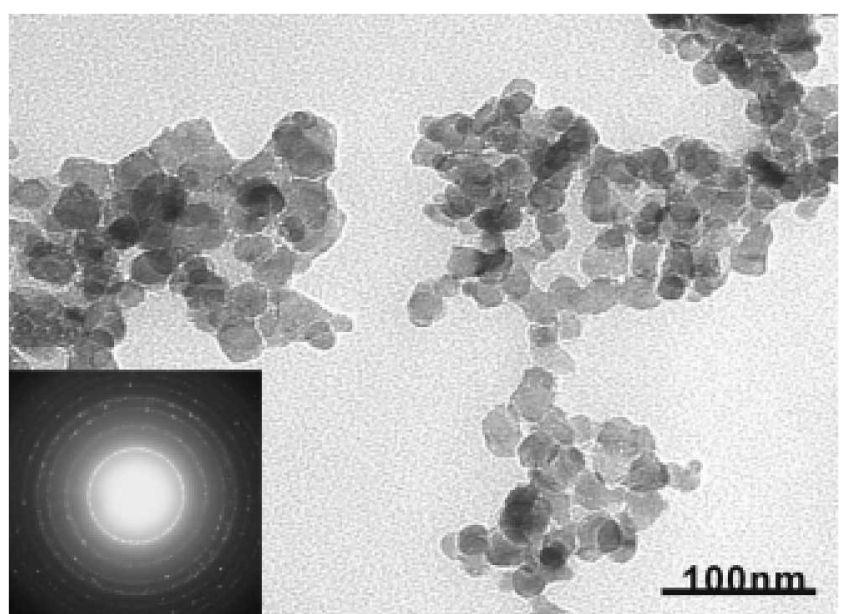

Figure 5. TEM bright field image of polycrystalline $\mathrm{TiO}_{2}$ nanoparticles and selected area diffraction patten. $\mathrm{TiO}_{2}$ nanoparticles were deposited at $600^{\circ} \mathrm{C}$.

at $122 \mathrm{eV}$. which is shifted from the $\mathrm{Nd}^{\mathrm{l}}$ peak position (118 $\mathrm{eV})^{-9}$ suggesting that $\mathrm{Nd}$ is present as $\mathrm{Nd}^{3-3.31}$

The surface morphology of the sample was examined by scanning electronic microscopy (SEM). Figure 4 is a SEM picture of the $\mathrm{Nd}$ doped $\mathrm{TiO}_{2}$ nanoparticles. The aggregated nanostructured $\mathrm{TiO}_{2}$ particles are visible. The micrograph confirms the nanometer size of the $\mathrm{TiO}_{2}$ particles. Although SEM micrographs can give a rough measure of the particle size. TEM was used for more accurate particle size measurement. Figure 5 shows a TEM bright field image with the diffraction pattem as an insert. The average particle size measured was about $22 \mathrm{~nm}$. consistent with the grain size measured by XRD. The electron diffraction pattern corresponds to that of $\mathrm{TiO}_{2}$. Figure 6 shows the DLS results. indicating that the $\mathrm{TiO}_{2}$ nanoparticles were distributed in the range of $20-25 \mathrm{~nm}$ with a short tail towards the larger particle size. The larger particles could not be eliminated even after extended sonication.

The photodegradation experiments were carried out on

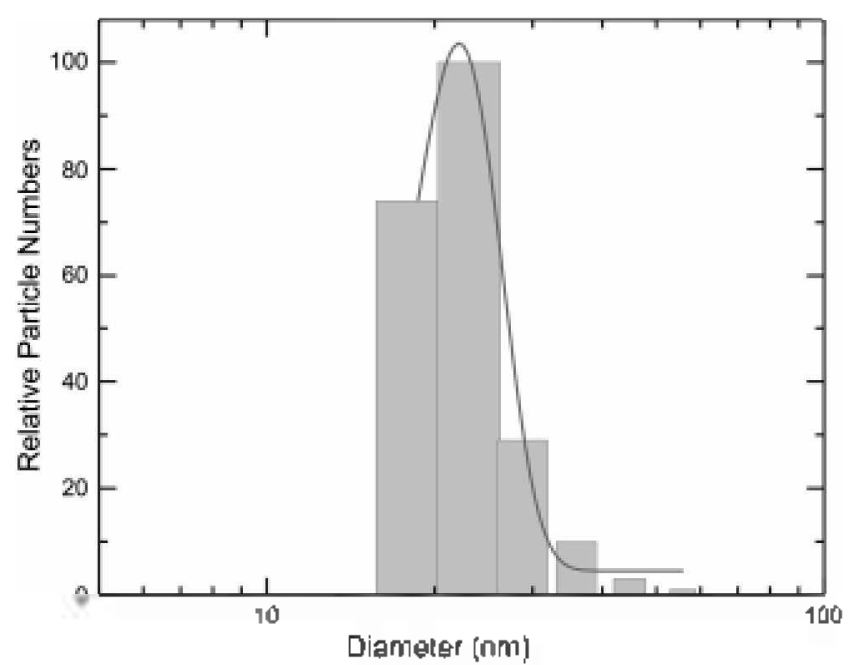

Figure 6. Particle size distribution of $\mathrm{TiO}_{2}$ nanoparticles obtained by dynamic light scattering.

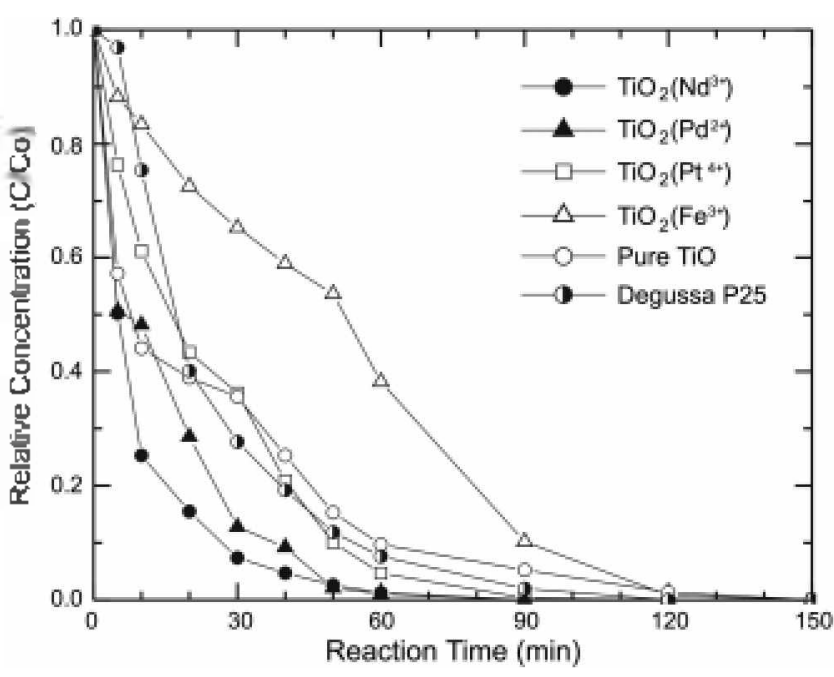

Figure 7. Photodegradation of 2-chlorophenol with Degussa P25, undoped $\mathrm{TiO}_{2}$ and different metal ion $\left(\mathrm{Nd}^{3+}, \mathrm{Pd}^{2+}, \mathrm{Pt}^{\mathrm{t}-}, \mathrm{Fe}^{3+}\right)$ doped $\mathrm{TiO}_{2}$ under a UV light source. Initial concentration of $2-\mathrm{CP} \mathrm{C}_{0}=50$ $\mathrm{mg}$ and volume $=1000 \mathrm{~mL}$ with $\mathrm{pH} 9.5$.

samples doped with transition metal Pd. Pt. Fe and lanthanide $\mathrm{Nd}$. The doping level in all four cases was kept constant at about 1 at.\%. The activities for the photodegradation for $2-$ $\mathrm{CP}$ are compared in Figure 7. The figure also shows the photoactivities of the undoped $\mathrm{TiO}_{2}$ nanoparticles and Degussa P25 standard. The results show that the activities for the photodegradation of 2-CP have been enhanced in most cases. In particular. for $\mathrm{Nd}$ doped $\mathrm{TiO}_{3}$. the time for $90 \%$ destruction of 2 -CP has been reduced to 25 minutes from 60 minutes in the case of undoped $\mathrm{TiO}_{2}$ and Degussa P25. The apparent quantum yield can be calculated. which is the ratio of the number of pollutant molecules destroy'ed to the number of photons absorbed. Assuming that the fraction of the absorbed photons by $\mathrm{TiO}_{2}$ is 1 . the apparent quantum yields were calculated for doped and undoped $\mathrm{TiO}_{2}$ and are shown in Table 1. The quantum yield of 2-C.P suspension with $\mathrm{Nd}$ doped $\mathrm{TiO}_{2}$ cataly st is almost 3 times that of pure $\mathrm{TiO}_{2}$ and 2.5 times that of Degussa P25. However. the Fe doped $\mathrm{TiO}_{2}$ had the lowest yield, which is only 0.4 times that of pure $\mathrm{TiO}_{2}$. The lack of enhancement of photocatalytic activity by Fe doping is not surprising. There have been previous studies that show similar results for $\mathrm{Fe}$ on the

Table 1. Estimations of initial photodegradation rate, UV photon tlux, and apparent quantum yield for aqueous solutions of 2-CP with doped and undoped $\mathrm{TiO}_{2}$ nanoparticles in the reactor

\begin{tabular}{|c|c|c|c|}
\hline Catalyst & $\begin{array}{l}\text { Initial rate } \\
10^{6} R^{\text {in }} \\
(\mathrm{mol} / \mathrm{min})\end{array}$ & $\begin{array}{l}\text { Photon flux } \\
10^{+} R_{\Delta(365)} \\
\text { (Einsteir/minl) }\end{array}$ & $\begin{array}{l}\text { Quantum yield } \\
\quad-10^{2} \Phi_{2 C P} \\
=R^{m} / R_{0(3(4)}\end{array}$ \\
\hline $\mathrm{TiO}_{2}\left(\mathrm{Nd}^{3+}\right)$ & $29.2 \pm 0.25$ & 4.42 & $6.61 \pm 0.06$ \\
\hline $\mathrm{TiO}_{2}\left(\mathrm{Pd}^{3-}\right)$ & $17.6 \pm 0.82$ & 4.42 & $3.98 \pm 0.19$ \\
\hline $\mathrm{TiO}_{2}\left(\mathrm{Pt}^{1+}\right)$ & $12.9 \pm 0.47$ & 4.42 & $2.92 \pm 0.11$ \\
\hline $\mathrm{TiO}_{2}\left(\mathrm{Fe}^{3-}\right)$ & $3.74 \pm 0.64$ & 4.42 & $0.84 \pm 0.14$ \\
\hline Pure $\mathrm{TiO}_{2}$ & $9.72 \pm 0.82$ & 4.42 & $2.20 \pm 0.19$ \\
\hline Degussa P25 & $11.7 \pm 0.25$ & 4.42 & $2.65 \pm 0.06$ \\
\hline
\end{tabular}


photodegradation of the vinyl clloride. ${ }^{13}$ The reason for the lack of photocatalytic activity enhancement by $\mathrm{Fe}$ is not completely understood but could be related to non-optimal valency of $\mathrm{Fe}$. the ionic radii of $\mathrm{Fe}$ and the attachment of phenol to $\mathrm{Fe}$. The accurate determination of $\mathrm{Fe}$ oxidation state when it is present in such low concentrations is difficult due to the problem of satisfactorily resolving the $\mathrm{Fe} \mathrm{3p}$ region of the XPS spectrum. Currently. experiments are being designed to increase the concentration of the dopants. which will make it easier to determine the Fe oxidation state.

The primary driving force in this research is to study the photocatalytic characteristics of $\mathrm{TiO}_{2}$ nanoparticles and the effect of metal ion doping on its performance. In photocatalysis. the number of free charges on the surface determines the efficiency of the catalyst. For large particles. the volume recombination of electrons and holes dominates. This largely reduces the numbers of free charges on the surface. deteriorating the photocatalytic activity. The recombination of hole $\left(\mathrm{h}^{-}\right)$-electron $\left(\mathrm{e}^{-}\right)$pairs are suppressed because the nanosize particles of $\mathrm{TiO}_{2}$ have many defect sites where photoexited electrons can be trapped. Also. photoreactivity increases with a decrease in the surface area of the nanoparticles. thereby increasing the efficiency of photocatalyst. For optimum efficiency there is a critical size below which the surface recombination of electrons and holes becomes dominant due to the increased surface to volume ratio. ${ }^{1532}$ The activity of $\mathrm{TiO}_{2}$ is also dopants dependent. Different dopants have different effects on impeding the transportation of electrons and holes from the interface to the surface. Consequently different dopants can have different effects on catalyst efficiency.

As discussed earlier. XRD results confirmed the presence of only the anatase phase in the $\mathrm{TiO}_{2}$ nanoparticles and that no separate dopant related phase is present in the particles. This suggests that the dopant ( $\mathrm{Fe}$. Pt. Pd. Nd) either goes to the substitution sites on $\mathrm{TiO}_{2}$ lattice or to the octahedral interstitial sites. For chlorophenol degradation. an oxidation reaction. the trapping of electrons is critical. In nanoparticles. electron trapping reduces surface recombination and allows holes to diffuse to the particle surface and participate in the oxidation reaction. Any dopant that effectively increases the localized positive charge will improve the oxidation of chlorophenols. The effective sizes of ions are shown in Table $2{ }^{33.34} \mathrm{Nd}^{3+}$ has the largest ionic radii. $0.983 \mathrm{~A}$. much larger than that of $\mathrm{Ti}^{++} .0 .605 \mathrm{~A}$. $\mathrm{Pd}^{2-}$ has ionic radii. which is also relatively' larger than that of $\mathrm{Ti}^{+-}$. $\mathrm{Fe}^{3+}$ and $\mathrm{Pt}^{4-}$, on the other hand have ionic radii that are relatively small and comparable to that of $\mathrm{Ti}^{4^{-}}$. The similarity of ionic radii promotes substitutional incorporation of the dopants. The substitutionally incorporated dopant is less useful in the charge trapping since the local charge distribution is only slightly disturbed. if at all. On the other hand. $\mathrm{Nd}^{3+}$ and $\mathrm{Pd}^{--}$ions are much larger than $\mathrm{Ti}^{4+}$. Therefore. it is energetically favorable for them to preferentially go into the larger octahedral interstitial sites in the anatase lattice ${ }^{35}$ The high oxygen affinities of $\mathrm{Nd}$ and Pd cause a strong dopant-oxygen bond. This effectively creates a localized positive charge around $\mathrm{Ti}$ and/or forms an
Table 2. Ionic radii for a coordination number of 6

\begin{tabular}{lccccc}
\hline Ions & $\mathrm{Fe}^{3-}$ & $\mathrm{Pd}^{2-}$ & $\mathrm{Pt}^{1+}$ & $\mathrm{Nd}^{3+}$ & $\mathrm{Ti}^{4-}$ \\
\hline Ionic radii $(\AA)$ & 0.645 & 0.86 & 0.625 & 0.983 & 0.605 \\
\hline
\end{tabular}

oxygen vacancy. Both of these possibilities help form electron traps, increasing the lifetime of holes.

Under the condition of efficient electron trappings. the interfacial transferring becomes easier for the holes. which finally react with water and oxygen to form more active hydroxyl radicals. It is the hydroxyl radicals that participate in the oxidation reaction of 2 -C.P. In our experiment. the $\mathrm{pH}$ value was kept constant and also there was excessive $\mathrm{O}_{2}$ supplied. Thus. the generation rate of hydroxyll radicals diffused into the aqueous solution is basically determined by the number of holes transferred to the surface of $\mathrm{TiO}_{2}$ solid phase. The holes. with larger quantity or longer lifetime. have a tendency to produce more radicals until a steady state. with a balance of the radical consumption and production. is reached. According to this pseudo-first-order degradation process. the destruction rate of 2-C.P aqueous solution can be addressed as:

$$
-\frac{d[C]}{d t}=K_{o p p}\left[O H^{*}\right][C]
$$

where $\left[O H^{*}\right]$ is the hydroxyl radicals concentration. [C] is 2-CP concentration. $t$ is reaction time and $K_{a p p}$ is apparent reaction rate which can be affected by the power of lamp. concentration of catalyst etc. ${ }^{36}$ Apparently with the same reactor geometry power of UV lamp and initial concentration of 2-CP and $\mathrm{TiO}_{2}$, the degradation rate or number of radicals is closely related to the dopant type. The chemical reaction and the ionic radii effects discussed above suggest that Fe does not help the 2-CP oxidation process at all and $\mathrm{Pt}$ helps only slightly. $\mathrm{Pd}$ and $\mathrm{Nd}$ can enhance the efficiency. especially $\mathrm{Nd}^{3+}$. having large ionic radii that causes the localized charging effect. ${ }^{37}$

\section{Conclusions}

We have synthesized doped and undoped $\mathrm{TiO}_{2}$ nanoparticles by MOCVD on a variety of substrates. Within a certain range of the growth temperatures the $\mathrm{TiO}_{2}$ nanoparticles were crystalline and had anatase structure. The particles were doped with a variety of transition metals and lanthanide ion dopants. The effect of the dopants $(\sim 1 \%)$ on the photocatalytic activity for the destruction of 2-C.P was measured. $\mathrm{Nd}$ doping was most effective in the enhancement of the photoactivity of the $\mathrm{TiO}_{2}$ nanoparticles. The $90 \%$ destruction time of 2-CP was reduced from 60 minutes for the undoped $\mathrm{TiO}_{2}$ nanoparticles to 25 minutes for the 1 at. $\% \mathrm{Nd}$ doped nano $\mathrm{TiO}_{2}$. The apparent quantum yield was 2.5 times that of Degussa $\mathrm{P} 25$ and 3 times that of undoped $\mathrm{TiO}_{2}$. The enlancement of the photocatalytic efficiency was related to the size differences between the host $\mathrm{Ti}^{+4}$ ionic radii and the dopant's ionic radii. Smaller ionic radii $\mathrm{Fe}^{3+}$ did not help the oxidation of 2-CP whereas all the larger ionic radii dopants 
did particularly $\mathrm{Nd}^{3+}$. $\mathrm{Fe}$. presumably, goes on the substitutional sites while $\mathrm{Pd}$ and $\mathrm{Nd}$ go on the interstitial sites. Further experiments, including near edge X-ray absorption fine structure (NEXAFS) and XPS. are being carried out to ascertain the position of the dopants in the $\mathrm{TiO}_{2}$ lattice.

Acknowledgment. This study was supported by research funds and facilities from Chosun University. Korea and University of Delaware. USA. 2001.

\section{References}

1. Hotchandani, S.: Kamat P. V. J. Electrochem. Soc. 1992, I39. 1630 .

2. Rensmo. H.: Keis. K.: Lindström. H.: Söedergren. S.: Solbrand. A.: Hagfeldt. A.: Lindquist. S.-E.: Wang. L. N.: Muhammed. M. $J$. Phws. Chem. 1997. B 101. 2598.

3. Bedja, I.: Kamat P. V. J. Phws. Chem 1995. 99.9182.

4. Bjorksten. U.: Moser. J.: Gratzel. M. Chem. Nater 1994. 6, 858

5. Litter. M. I.: Navio. I. A. J. Photochem. Photobiol. A: Chem. 1994. 84. 183.

6. Bickley. R. I.: Gonzalez-Carreno. T.: Gonzalez-Elipe. A. R.: Munllera, G. Palmisano, L. J. Chem Soc. Faradov Trans. 1994. 90.2257

7. Murata, Y: Fukuta. S.: Ishikawa, S: Yokovama, S. Sol Energy Mater Sol. Cels 2000. 62. 157.

8. Wang. Y: Cheng. H.: Hao. Y: Ma. J.: Li. W.: Cai. S. J. Mater Sci. 1999.34. 3721

9. Bach. U: Lupo. D: Comte. P: Moser. J. E: Weissortel. F: Salbeck: J: Spreitzer. H: Gratzel. M. Noture 1998, 395, 583.

10. Nozik A. J: Memming. R. J. Phws. Chem. 1996. 100. 13061

11. Grela, M. A.: Brusa, M. A.: Colissi, A. I. J. Phns, Chent 1997. B 101. 10986

12. Kink-Othmer Encyclopedia of Chemical Techologv: Howe-Grant. M.. Ed.: John Wiley \& Sons. Inc.: 1997: Vol. 24. p 225

13. Palmisano. L: Augugliaro. V.: Sclafani. A.: Schiavello, M. $J$. Phvs. Chent 1988. 92.6710

14. Choi, W.: Termin, A.: Hoffermann, M. R. J. Phws. Chem 1994.
98. 13669

15. Zhang. Z; Wang. C.C.: Zakaria. R.: Ying. J. Y. J. Phws. Chent. 1998. B 102. 10871

16. Wang. C.-C.: Zhang. Z.: Ying. J. Y. Xano Stuctwed Mater 1997. 9.583 .

17. Cheng, H: Ma. J.: Zhao. Z; Qi, L. Chent. Mater 1995. 7,663.

18. Wang. Y.: Hao. Y.: Cheng. H.: Ma, J.: Xu, B; Li, W: Cai. S. J. Mater. Sci. 1999. 3+.2773.

19. Akhtar. M. K.: Xiong. Y.: Pratsinis. S. E. $A C C h E J$. 1991. 37. 1561.

20. Ding. Z.: Hu. X.: Lu. G. Q.: Yue. P.-L.: Greentield. P. F. Langmuir 2000. 16.6216

21. Okuyama, K.: Kousaka. Y; Tohge, N.; Yamamoto, S.: Wu. J. J.: Flagan, R. C.: Seinfeld, J. H. AIChE J. 1986, 32. 2010

22. Okuyama, K; Jeung, J.-T; Kousaka. Y. Chem. Eng Sci. 1989 , th. 1369.

23. Okuyama. K.: Ushio. R.: Kousaka. Y.: Flagan. R. C.: Seinfeld. T. H. $A I C h E J .1990 .36 .409$

24. Ismat Shah. S: Li, W. unpublished

25. Freeware form http: www cepl t ac uh tutorial xfit-95:

26. Cullity, B. D. Elentents of A-Ran Liffinaction' Addison-Wesley: Menlo Park. CA. 1978

27. Sclafani. A.: Palmisano. L.: Davi. E. J. Photochem. Photobiol. A. Chem. 1991. 56.113.

28. Vidal, A.: Herrero, J:: Romero. M: Sanchez. B.: Sanchez. M. J. Photochem. Photobiol A: Chent 1994, 79,213.

29. Handbook of A-ray Photoelectron Spectroscops, Wagner, C. D. Riggs. W. M.: Davis. L. E.: Moulder. I. F.: Muilenberg. G. E.. Eds.: Perkin-Elmer corporation: 1979.

30. Sen1. S. K.: Riga. J.: Verbist. T. Chem. Phus. Lett. 1976. 39.560.

31. Sarma. D. D.; Rao. C. N. R. J. Electron Sipectrosc. Relate. Phenton. 1980. 20,25

32. Beydoun, D: Amal. R.: Low. G.: McEvoy, S. J. Nanoparticle Res. 1999. 1. 439 .

33. Shant1on1. R. D. Acta Constallogr: 1976. A 32.751.

34. Shannon1. R. D.: Prewitt. C. T. Acta Chystallog: 1969. B 25. 925.

35. Jung. O. J; Kim. I. K.; Saha, I. S. (Structure and size distribution of $\mathrm{Nd}(\mathrm{III})$ doped $\mathrm{TiO}_{2}$ nanoparticle) Haterial Science and Engineering $B$. in press.

36. Fotou. G. P.: Pratsinis. S. E. Chem. Eng. Comm 1996. 151. 251

37. Jung. O. T. Bull. Korean Chem. Soc. 2001. 22. 1188. 